\title{
A DIAGNOSTIC APPROACH TO EXAMINING THE FUNCTIONAL DISORDERS OF THE SACROILIAC JOINTS
}

\author{
Ilko Todorov' ${ }^{1}$ Ara Kaprelyan² \\ ${ }^{1}$ Clinic of Physiotherapy and Rehabilitation and ${ }^{2}$ First Clinic of Neurology, \\ St. Marina University Hospital of Varna
}

\begin{abstract}
PURPOSE: Nowadays most physicians experience problems with the proper diagnosis of the sacroiliac joint dysfunction. It is mainly due to the presence of numerous diagnostic tests of unclear clinical reliability and insufficient research. The objective of this study is to develop a highly efficient diagnostic approach to the sacroiliac dysfunction.

MATERIAL AND METHODS: A total of 120 patients with dysfunction of the sacroiliac joint were examined by means of 7 tests. These tests were provisionally divided according to their association with testing of the real movement in the sacroiliac joint into specific tests such as De Winter phenomenon, spine-test and Rosina test and non-specific ones such as Patrick, Mennel I, pseudo-Lassegue and 3-step test.

RESULTS: Against the very common initial data from all the tests a very distinctive result difference after manual therapy was present. The non-specific tests demonstrated a low level of clinical reliability when applied right after restoring the joint functionality. On the other hand, the specific tests presented with a clinical reliability of more than $\mathbf{9 1 \%}$.
\end{abstract}

CONCLUSION: An eventual positive result of two specific tests mentioned above provides a diagnostic accuracy of $\mathbf{9 4 \%}$ concerning the functional disorder/blockage of the sacroiliac joint.

Key words: functional disorder, sacroiliac joint, manual therapy, specific tests, non-specific tests

\section{INTRODUCTION}

Manual medicine focuses on the physiology, pathophysiology and the elimination of the reversible functional disorders of the musculoskeletal apparatus. Joint mobility reduction associated with the so-called blockage is placed in the foundation of

Address for correspondence:

Ilko Todorov, $M D, P h D$

Clinic of Physiotherapy and Rehabilitation

St. Marina University Hospital of Varna

1 Hristo Smirnenski Street

9010 Varna, Bulgaria

Tel. +359898654365

e-mail: ilkotodorov@gmail.com

Received: August 30, 2012

Accepted: March 04, 2013 the manual therapy. To this term refer any functional disorders of the joints of the vertebral column (Junghans segments) and the periphery associated with hypomobility and diminished joint play. There are two kinds of joint mobility known such as functional mobility characterized by the active range of motion and passive mobility or joint play. Both could be tested manually and if necessary, with an $\mathrm{x}$ ray identifying some possible restriction reasons.

First descriptions of the sacroiliac joint movement were made by Zaglas (1851) and Duncan (1854). In 1863, von Luschka proved from anatomical aspect the diarthrodial characteristics of the joint. Later on, the sacroiliac joint was studied by Colachis, Weisl, Frogerio, etc. First calculations about the range of joint motion of 2,7 $\mathrm{mm}$ were performed by Grieve in 1976. 
Sacroiliac joint surfaces of sacrum and ilium are congruent, the shape being either boomerangsimilar or C-shape. The caudal part of the joint is by about $1 / 3$ longer than the cranial one. The ends of the joint surface are denoted as poles. In growings, the joint surface is situated between S1 and S3. The place of the surface bend is approximately at the level of S2. The joint surface of an average joint is $6-8 \mathrm{~cm}$ in length and $2-3 \mathrm{~cm}$ in width. The upper and the lower pole are situated at an angle of $100-120^{\circ}$. They have such a dimensional orientation that the upper pole is pointing cranially and the lower one does dorsally.

Kapandji describes the relation between the vertebral column shape and that one of facies auricularis. If the anatomical curves of the vertebral column are reduced, so is the one of facies auricularis, thus the abovementioned angle increases in size. On the contrary, if the curves of the vertebral column are increased, so is the one of facies auricularis, thus the angle reaches $90^{\circ}$ in some individuals. Most authors agree about the concept that any axes of movement are crossed in a spot at the level of S2 in the zone of lig. interosseum, just dorsally to the bend of the joint surface. The frontal axis is situated horizontally at the height of S2 and movement nutation and couternutation occur here. They could be described as flexion and extension, too. The longitudinal axis is vertically located and divides sacrum to right and left parts. This axis is associated with the rotation of sacrum that is considered to be quite minimal.

Concerning the innervations of the sacroiliac joint structures, there are some discrepancies in the statements. According to the German anatomists, the joint is innervated mainly by S1, but also by some roots from S2. In addition, $n$. glutaeus superior (L4/ L5) delivers some roots to the joint. Rr. dorsales from S2 and S3 reach ligg. sacroiliaca dorsalia, some of them reaching the anchor of $m$. glutaeus maximus. The sacrospinal and sacrotuberal ligaments are innervated by S3 and S4. Kissling et al. (1997) describe numerous thick, myelinated nerve bundles in the joint capsule thus proving the high receptor density in this structure.

In the English literature, an emphasis is made on the importance of the neuroanatomic specifications of the innervation of the different structures of the sacroiliac joint for the manual diagnosis and therapy.
The internal part of the synovial capsule and the ligaments are provided with non-myelinated nerve fibers conducting the pain and temperature sensory information. The joint capsule is innervated by myelinated and non-myelinated nerve bundles. The dorsal parts of the sacroiliac joint receive fibers from L3-S3 and the frontal ones do from L2-S2. The dorsal joint structures receive innervations from $r$. dorsales of L4-S1 and from rr. anteriores of L2-S2.

Recently, the innervation of the sacroiliac joint is comprehensively evaluated $(4,7,12)$. This process is conducted almost entirely by the dorsal sacral roots (6). Fetal pelvis dissections confirm that the innervation of the sacroiliac joint originates from $r r$. dorsales as there are neurofilaments in the dorsal mesenchyme only. Other investigators discover zones of hypoesthesia after an intra-articular administration of an anesthetic in the sacroiliac joint in skin zones innervated by $r$. dorsales only.

The histological analysis of the sacroiliac joint confirms the presence of nerve root fibers in the joint capsule and the nearby ligaments. Samples taken from the ventral part of microscopically normal, but in chronic pain sacroiliac joints consist of capsular ligament tissue. The microscopic investigations assure the presence of nerve bundles and of individual axons. The nerve bundles consist of myelinated as well as non-myelinated nerve fibers, two morphologic types of Pacini-similar encapsulated mechanoreceptors and a single mechanoreceptor of another kind. This proves the direct pain and proprioception from the sacroiliac joint.

The recent manual therapeutic practice affirms that the sacroiliac joint is not only reflex-associated with the vertebral column, but also often gets blocked. In the classic medicine, the 'distortion' or 'blockage' of the sacroiliac joint is an approved reason for low back pain or sciatica. In 1933, Ghormley first used the term of 'sacroiliac blockage' to describe the socalled facet syndrome. Nowadays ignoring that type of pathology by the manual therapists leads to an incomplete functional recovery after manipulations of the vertebral column, less efficient pain reduction and to a very high relapse risk, having in mind the reflex-associated relations. An accurate diagnosis of the functional disorders of the sacroiliac joint followed by manual therapy is a highly effective therapeutic model. 
Pelvic ring bears the important mechanical function to resist and distribute the incoming forces from cranially and caudally. In upright position, the weight of the body is transferred to the promontorium. Further on, the weight is distributed through the sacroiliac joints towards the acetabuli. If at that level the force of the weight is represented as a sum of vectors, then there would be a smaller lateral and a greater caudal force component. The caudallyoriented weight force transforms into a pressure in the both hip joints while the lateral force component causes a splitting away of the symphysis surfaces. A sudden, surprising and stronger mechanical stress could cause a relative slipping of the joint surfaces one to another causing the joint to get into a functional insufficiency known also as blockage.

Clinical manifestations of the sacroiliac blockage are the following:

* one-sided, progressing towards the gluteal region pain,

* asymmetric loading of the lower limbs as some sports such as golf, skating, skateboard etc. and some physical activities as climbing stairs, getting upright from sitting position, getting in and out of a vehicle aggravate the symptoms,

* nature and projection of the pain generated from the sacroiliac joint could vary spreading in certain cases towards the gluteal region, the loins and even zones of the lower limbs. In such cases, the patients should be thoroughly questioned in order to define the innervation model,

* m. piriformis, $m$. glutaeus maximus and $m$. erector spinae fulfill a first grade stabilizing role for the sacroiliac joint and it is quite logic in case of a joint blockage to get spastic. That could be assured by proper palpation,

* a spastic $m$. tensor fasciae latae palpated on the opposite side is a very typical sign of the sacroiliac blockage.

Because of the small actually limited range of motion the patients very rarely experience the problem immediately. Usually, several days and in some cases, even weeks are needed, during which the reflex-associated structures get into dysfunction presenting with discomfort and pain when moving.
In their clinical practice, manual therapists use more than 20 tests designed for the diagnosis of the sacroiliac functional disorders. Profound research about their reliability is absent. Usually, the therapists apply two or three tests, thus securing the proper diagnosis.

Which are the most accurate tests?

To answer this question, a major principle of manual medicine should be reminded: The restoration of movement in the joint affected is first-grade evidence about the effect of the manual therapy.

Some of the most popular sacroiliac tests do not actually reveal the joint mobility, but are based on the subjective feeling of pain during certain movements:

* Patrick

* Mennel

* pseudo-Lassegue

* 3-step test.

If we observe which tests actually check the absence or presence of movement in the sacroiliac joint, the number that comes out is greatly reduced. Major anatomic landmarks for diagnosing the movement presence in a certain sacroiliac joint are the anterior superior iliac spine (ASIS) and the posterior superior iliac spine (PSIS). PSIS is much more comfortable to be examined where the spinous process of L5 could assist.

The tests that directly follow the movement in the sacroiliac joints could be characterized as specific as they are affected from pathology in other anatomic structures nearby or reflex-associated to a lesser extent. A clarification is appropriate here that due to the specific anatomic structure of the sacroiliac joint and the extremely durable bonds, the movement is in fact of minimal amplitude. In vivo-measured angular movements between ilium and sacrum are estimated to be $1-3^{\circ}$. During nutation in the transversal axis at the level of L2 a range of motion of about 0,8 $3,2^{\circ}$ is measured. The translation movements being maximal at the level of S1 are about the same. All that means that even for a highly qualified examiner, the feeling in palpation for a movement is of just several millimeters.

\section{MATERIAL AND METHODS}


In the Clinic of Physiotherapy and Rehabilitation, St. Marina University Hospital of Varna, Bulgaria, during the period 2007-2011 a total of 120 patients with dysfunction of the sacroiliac joint were examined by using of a group of seven tests. These tests were provisionally divided according to their association with testing of the real movement in the sacroiliac joint into specific tests such as De Winter phenomenon, spine-test and Rosina test and non-specific ones such as Patrick, Mennel I, pseudoLassegue and 3-step test.

\section{RESULTS}

The results from the clinical application of these seven tests before and after manual therapy at the first patient's visit are demonstrated on Fig. 1.

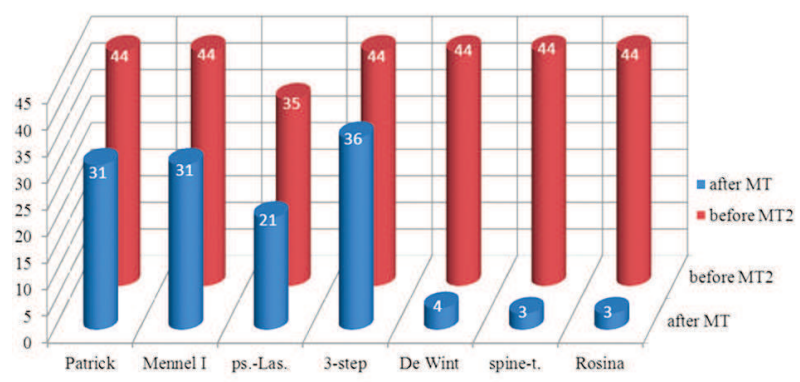

Fig. 1. Test results before and after manual therapy at first patient's visit

Against the very common initial data from all the tests a very distinctive result difference after manual therapy was present. The non-specific tests demonstrated a low level of clinical reliability when applied right after restoring the joint functionality. This could be due to the existing neuro-reflexassociated accompanying reactions of increased muscle tone in the lumbo-sacral and gluteal regions. On the other hand, the specific tests presented with a clinical reliability of more than $91 \%$.

\section{DISCUSSION}

The false-positive results after manual therapy could be eliminated if two specific tests were consecutively applied. There was a coincidence of false-positive results after manual therapy in two cases such as positive De Winter phenomenon and spine-test. Negative Rosina test in these cases could be interpreted as restored joint movements accompanied by a severe muscle disbalance that is, usually, the most probable reason for mistake when performing specific tests. In this case, the non-specific tests led to two positive and two negative results. If we compare the accuracy of the specific test among themselves, the spine-test shows a minimal superiority in terms of diagnostic accuracy. Concerning Rosina test, we observe a reflex-associated phenomenon that is scientifically explained yet, which is, obviously, related to a lower extent with the objective factors influencing upon the other specific tests.

Newly-published investigations reveal certain important peculiarities of the anatomy and physiology of the sacroiliac joint $(1,10,13)$ as well as of pain features and pain management $(2,3,5,14)$. Sacroiliac joint dysfunction is assessed, too (15), e.g. in spondyloarthritis (11). The results from the application of manipulative therapy techniques in sacroiliac joint syndrome are discussed (8).

\section{CONCLUSION}

We could recommend the following effective diagnostic approach:

1. Clinical patient's history

2. Spine-test followed either by De Winter phenomenon, or by Rosina test. The last is particularly effective in patients with high body mass.

Eventually positive results of two specific tests mentioned above provide a diagnostic accuracy of $94 \%$ of a functional disorder/blockage of the sacroiliac joint under the condition absent structural anomaly.

Structural deteriorations should be always considered highly possible if after applying the manual manipulations in two consecutive patient's visits a restoration of the sacroiliac movement does not occur at all.

\section{REFERENCES}

1. Arumugam, A., S. Milosavljevic, S. Woodley, G. Sole. Evaluation of changes in pelvic belt tension during 2 weight-bearing functional tasks.- J. Manipulative Physiol. Ther., 35, 2012, No 5, 390-395.

2. Ashman, B., D. C. Norvell, J. T. Hermsmeyer. Chronic sacroiliac joint pain: fusion versus 
denervation as treatment options.- Evid. Based Spine Care J., 1, 2010, No 3, 35-44.

3. Fortin, J. D., Dwyer A.P., West S., J. Pier. Sacroiliac joint: Pain referral maps upon applying a new injection/arthrography technique. Part I: Asymptomatic volunteers.- Spine, 19, 1994, No 13, 1475-1482

4. Fortin, J. D., R. O. Kissling, B. L. O’Connor, J. A. Vilensky. Sacroiliac joint innervation and pain.Am. J. Orthop., 28, 1999, No 12, 687-690.

5. Fortin, J. D., J. A. Vilensky, G. J. Merkel. Can the sacroiliac joint cause sciatica?- Pain Physician, 6, 2003, No 3 269-271.

6. Grob, K. R., W. L. Neuhuber, R. O. Kissling. Die Innervation des Sakroiliakalgelenkes beim Menschen.- Z. Rheumatol., 54, 1995, No 2, 117-122.

7. Hansen, H., L. Manchikanti, T. T. Simopoulos, P. J. Christo, S. Gupta, H. S. Smith, et al. A systematic evaluation of the therapeutic effectiveness of sacroiliac joint interventions.- Pain Physician, 15, 2012, No 3, E247-E278.

8. Kamali, F., E. Shokri. The effect of two manipulative therapy techniques and their outcome in patients with sacroiliac joint syndrome.- J. Bodyw. Mov. Ther., 16, 2012, No 1, 29-35.

9. Kissling, R., B. A. Michel. Das Sakroiliakalgelenk. Bücherei des Orthopäden. Stuttgart, Enke, 1997.

10. Solonen, K. A. The sacroiliac joint in the light of anatomical, roentgenological and clinical findings.Acta Orthop. Scand. Suppl., 27, 1957, 1-127.
11. Spadaro, A., A. Iagnocco, G. Baccano, F. Ceccarelli, E. Sabatini, G. Valesini. Sonographic-detected joint effusion compared with physical examination in the assessment of sacroiliac joints in spondyloarthritis.- Ann. Rheum. Dis., 68, 2009, No 10, 1559-1563.

12. Vilensky, J. Innervation of the joint and its role in osteoarthritis.- In: Osteoarthritis. K. Brandt, M. Doherty, L. Lohamander, eds. Oxford, Oxford University Press, 1998, 176-188.

13. Vleeming, A., M. D. Schuenke, A. T. Masi, J. E. Carreiro, L. Danneels, F. H. Willard. The sacroiliac joint: an overview of its anatomy, function and potential clinical implications.- J. Anat., 221, 2012, No 6, 537-567.

14. Vora, A. J., K. D. Doerr, L. R. Wolfer. Functional anatomy and pathophysiology of axial low back pain: disc, posterior elements, sacroiliac joint, and associated pain generators.- Phys. Med. Rehabil. Clin. N. Am., 21, 2010, No 4, 679-709.

15. Zelle, B. A., G. S. Gruen, S. Brown, S. George. Sacroiliacal joint dysfunction: evaluation and measurement.- Clin. J. Pain, 21, 2005, No 5, 446-455. 